\title{
Pengelolaan sumberdaya perikanan rawa gambut untuk meningkatkan perekonomian masyarakat Desa Tanjung Taruna Kabupaten Pulang Pisau
}

\author{
Shinta P. Yuptriani ${ }^{1}$, Muhammad Rizal ${ }^{1}$, Agung Prasetyo ${ }^{1}$, Riza Fahlifi ${ }^{1}$, Josua Situmorang ${ }^{2}$, \\ Dhea Rahmadini ${ }^{2}$, Enrico Rafael Siahaan ${ }^{2}$, Deden Priyatna Sumantri ${ }^{2}$, Megawati Sinambela ${ }^{3}$, \\ Rossyta Aprilyani ${ }^{3}$, Achmad Faried Rindhianto ${ }^{1}$, Kevin Agus Trianto ${ }^{1}$, Wendi Setiawan ${ }^{1}$, Dewi \\ Anggrieni $^{1}$, \& Sri Endang Agustina Rahayuningsih ${ }^{1 *}$
}

${ }^{1}$ Program Studi Agroteknologi, Jurusan Budidaya Pertanian, Fakultas Pertanian, Universitas Palangka Raya ${ }^{2}$ Program Studi Teknologi Industri Pertanian, Jurusan Budidaya Pertanian, Fakultas Pertanian, Universitas Palangka Raya

${ }^{3}$ Program Studi Peternakan, Jurusan Budidaya Pertanian, Fakultas Pertanian, Universitas Palangka Raya

* agustina_rahayuningsih@agr.upr.ac.id

\begin{abstract}
Abstrak. Desa Tanjung Taruna adalah salah satu di wilayah Kecamatan Jabiren Raya, Kabupaten Pulang Pisau, Provinsi Kalimantan Tengah. Desa ini termasuk dalam kawasan rawa gambut dan daerah aliran sungai Kahayan. Desa ini secara geografis terletak di daerah aliran sungai, membuat hasil perikanan melimpah, tetapi masyarakat setempat terkendala pemasaran dan pengolahan sumberdaya perikanan. Sebagian besar penduduk memiliki mata pencaharian sebagai nelayan. Kegiatan Program Hibah Bina Desa (PHBD) ini bertujuan untuk memberikan pelatihan dan pendampingan guna meningkatkan pengetahuan, keterampilan dan kesejahteraan masyarakat. Metode kegiatan dilakukan dengan melakukan sosialisasi, pelatihan dan pendampingan tentang pengolahan ikan menjadi produk abon dan bakso guna menambah nilai jual ikan tersebut yang sebelumnya hanya dijual dalam bentuk ikan segar dan ikan asin. Hasil kegiatan menunjukkan partisipasi peserta cukup bagus dengan jumlah peserta pelatihan sebanyak 38 orang. Berdasarkan hasil evaluasi pelatihan diketahui bahwa $95,5 \%$ peserta pelatihan menjadi bertambah pengetahuan dan dapat mengolah hasil ikan dari sumberdaya alamnya untuk diolah menjadi bakso ikan dan abon ikan dapat dijadikan sumber pendapatan rumah tangga.
\end{abstract}

Kata Kunci: pengolahan ikan, desa Tanjung Taruna, rawa gambut, abon ikan, bakso ikan

\begin{abstract}
Tanjung Taruna Village is one of the areas in Jabiren Raya Subdistrict, Pulang Pisau Regency, Central Kalimantan province. This village is included in the peat swamp area and the Kahayan river basin. This village is geographically located in a watershed, making fishery products abundant, but the local community is constrained by marketing and processing fishery resources. Most of the population works as fishermen. This Village Development Grant Program (PHBD) activity aims to provide training and assistance to increase knowledge, skills and community welfare. The method of activity is carried out by conducting socialization, training and mentoring on the processing of fish into shredded and meatball products in order to increase the sale value of these fish which previously were only sold in the form of fresh fish and salted fish. The results of the activity showed that the participation of the participants was quite good with 38 participants. Based on the results of the training evaluation, it is known that $95.5 \%$ of the training participants have increased knowledge and can process fish products from their natural resources to be processed into fish balls and fish floss can be used as a source of household income.
\end{abstract}

Keywords: fish processing, Tanjung Taruna village, peat swamp, shredded fish, fish meatballs

To cite this article: Yuptriani, S. P., M. Rizal., A. Prasetyo., R. Fahlifi., J. Situmorang., D. Rahmadini., E. R. Siahaan., D. P. Sumantri., M. Sinambela., R. Aprilyani., A. F. Rindhianto., K. A. Trianto., W. Setiawan., D. Anggrieni., \& S. E. A. Rahayuningsih. 2020. Pengelolaan sumberdaya perikanan rawa gambut untuk meningkatkan perekonomian masyarakat Desa Tanjung Taruna Kabupaten Pulang Pisau. Unri Conference Series: Community Engagement 2: $372-$ 378. https://doi.org/10.31258/unricsce.2.372-378

(C) 2020 Authors

Peer-review under responsibility of the organizing committee of Seminar Nasional Pemberdayaan Masyarakat 2020 


\section{PENDAHULUAN}

Desa Tanjung Taruna adalah salah satu di wilayah Kecamatan Jabiren Raya, Kabupaten Pulang Pisau, Provinsi Kalimantan Tengah. Desa ini termasuk dalam kawasan rawa gambut dan daerah aliran sungai Kahayan. Desa ini secara geografis berada diantara Jalan Trans Kalimantan dan Sungai Kahayan. Jarak tempuh Desa Tanjung Taruna ke ibukota Provinsi Kalimantan Tengah \pm 26 kilometer. Jalan menuju lokasi Desa Tanjung Taruna, harus terlebih dahulu masuk ke dalam gang dari Jalan Trans Kalimantan. Meski jaraknya hanya 6,3 km, perjalanan yang ditempuh mampu mencapai 30 menit 3 (Andriani et al, 2018). Hal ini karena kondisi jalan yang hanya bisa dilalui menggunakan kendaraan roda dua (Gambar 1). Jalur transportasi air menuju Desa Tanjung Taruna (Gambar 2).

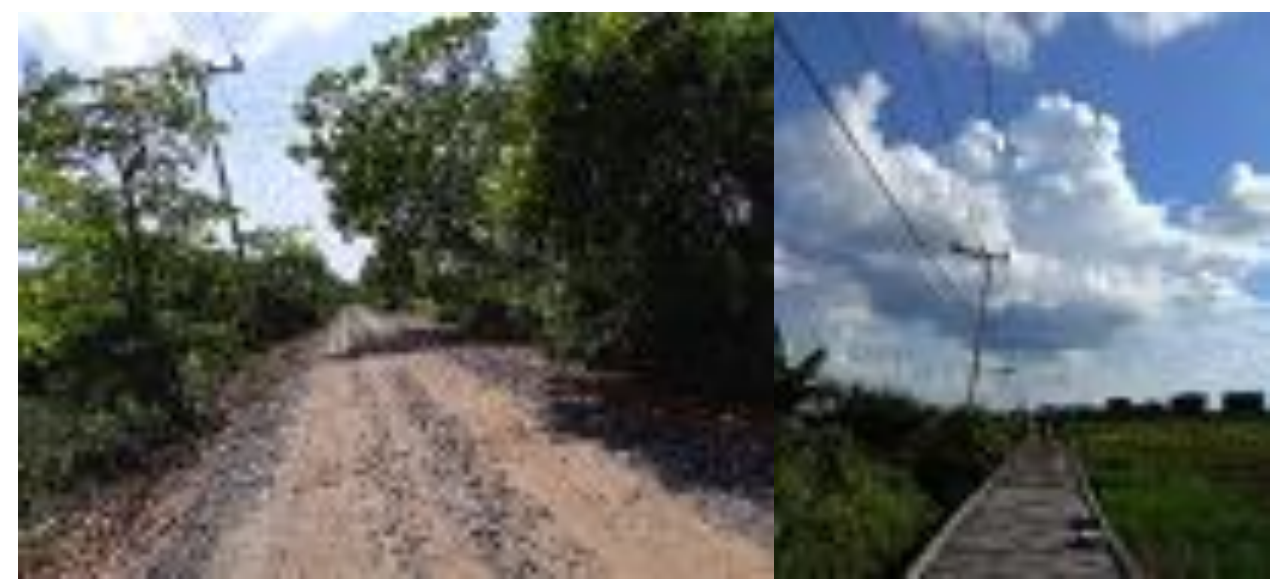

Gambar 1. Kondisi Jalan Menuju Desa Tanjung Taruna

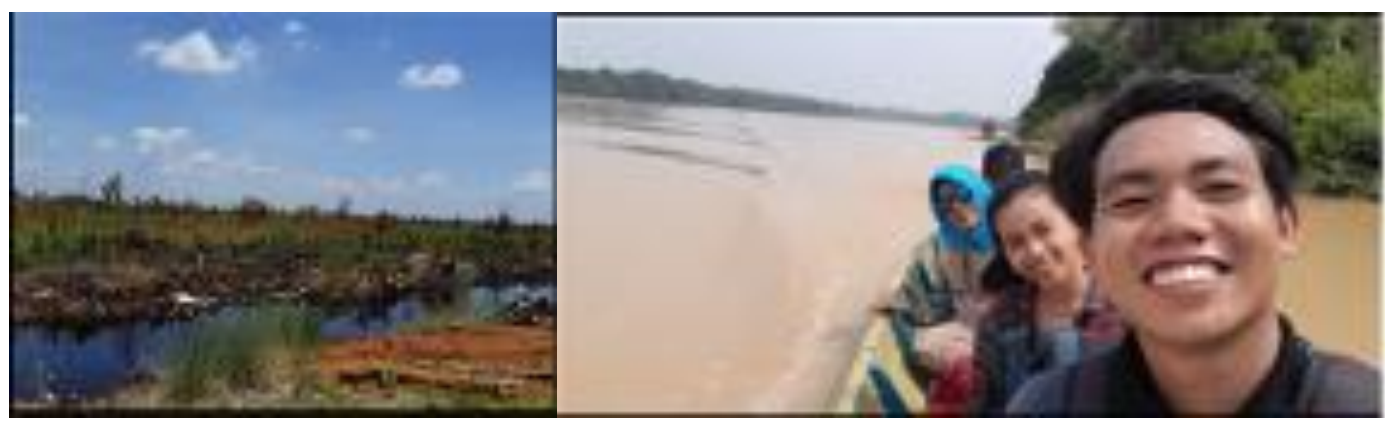

Gambar 2. Jalur transportasi air menuju Desa Tanjung Taruna

Mayoritas sumber pendapatan warga Tanjung Taruna berasal dari mata pencaharian nelayan. Desa Tanjung Taruna memiliki jenis ikan antara lain; ikan patin (Pangasianodon hypophthalmus), ikan gabus (Channa striata), ikan lais (Kryptosterus bicirrhis), ikan baung (Mystus), ikan seluang (Rasbora), ikan papuyu (Anabas testudineus), ikan biawan (Helostoma temminckii), ikan kapar (Belontia hasselti), ikan kehung (Channa lucius), ikan lele (Clarias), ikan toman (Channa micropeltes), ikan sepat (Trichopodus trichopterus), ikan kerandang (Channa pleuropthalma). Warga biasanya mencari ikan di sungai. Ikan ini dijual dalam bentuk ikan segar (Gambar 3) maupun diolah terlebih dahulu menjadi ikan asin (Gambar 3) (Andriani et al, 2018). Guna memanfaatkan potensi ikan dan meningkatkan nilai jual, maka masyarakat Desa Tanjung Taruna perlu adanya inovasi yang dikembangkan untuk dapat mengatasi permasalahan yang ada pada kondisi desa tersebut. 


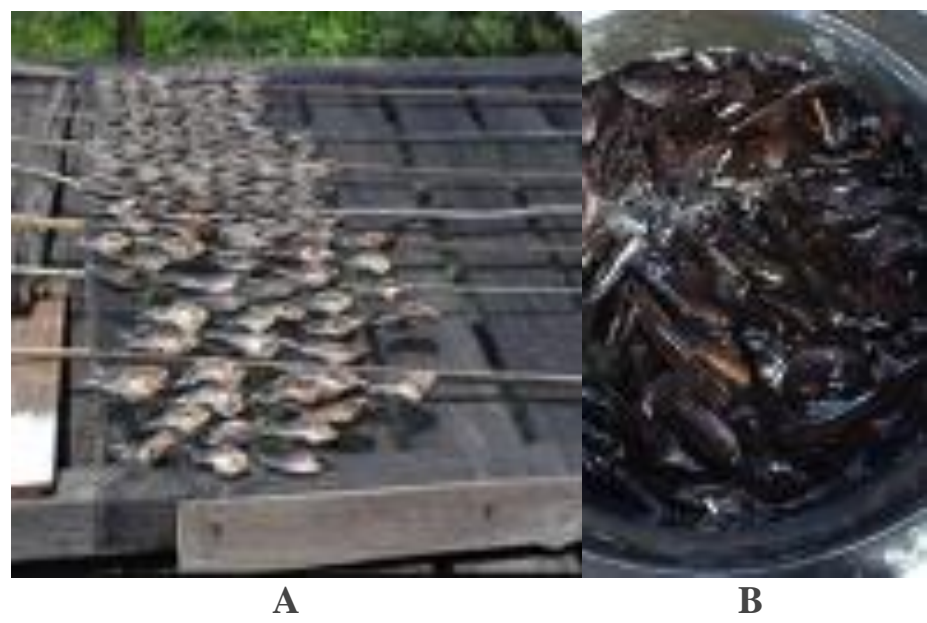

Gambar 3. A. Ikan asin. B. Ikan segar

Berdasarkan hasil pengabdian masyarakat Pratama dkk (2017) teknologi pengolahan hasil perikanan dapat meningkatkan nilai tambah ikan hasil tangkapan dan dapat meningkatkan pengetahuan serta keterampilan kepada masyarakat mengenai pengolahan hasil perikanan. Berdasarkan hasil pengabdian masyarakat Ika dkk (2017) hasil yang diperoleh bahwa $100 \%$ peserta dapat menerapkan ilmu pengetahuan dan teknologi, dapat mengembangkan komoditi lokal ikan menjadi produk yang memiliki nilai jual yang lebih tinggi.

Permasalahan yang dialami Desa Tanjung Tarun dikenal sebagai kawasan penghasil ikan. Ikan tersebut merupakan hasil tangkapan masyarakat dari sungai Kahayan. Namun karena kurangnya pengetahuan dan keterampilan masyarakat terkait pengolahan ikan, dalam proses pemasarannya masyarakat hanya menjual bahan mentah yang berupa ikan kering dan ikan segar.

Pengabdian ini bertujuan meningkatkan pengetahuan dan keterampilan masyarakat desa Tanjung Taruna mengenai sumberdaya alam perikanan yang melimpah, serta mengembangkan pengolahan hasil perikanan yang secara langsung berdampak kepada kehidupan sosial dan peningkatan pendapatan di desa tersebut.

\section{METODE PENERAPAN}

Jangka waktu penyelesaian kegiatan dilaksanakan selama 6 (enam) bulan, dimulai pada bulan Juni hingga November 2019 bertempat di Desa Tanjung Taruna, Kecamatan Jabiren, Kabupaten Pulang Pisau, Provinsi Kalimantan Tengah. Kegiatan sosialisasi dilakukan pada hari Selasa 27 Agustus 2019. Mitra yang terlibat dalam pengabdian ini adalah Ibu - Ibu Pembina Kesejahteraan Keluarga (PKK) Desa Tanjung Taruna. Untuk meningkatkan pendapatan masyarakat di Desa Tanjung Taruna dilakukan dengan memberi pelatihan pembuatan abon dan bakso ikan patin dan ikan gabus. Pelatihan dilakukan dengan berbagai tahapan proses, yaitu: 1) tahap persiapan, yaitu survei tempat dilaksanakannya pelatihan, jumlah peserta, menyusun bahan dan alat yang akan disiapkan pada saat pelatihan, menyiapkan materi praktek pembuatan abon dan bakso ikan yang akan diberikan pada pelatihan. 2) tahap pelaksanaan, yaitu kegiatan dilaksanakan pada hari Sabtu 14 September 2019 Pukul 08.00-15.30 WIB di aula kantor desa.

Pelatihan diawali dengan pemberian materi dalam bentuk manual/panduan bagaimana tahapan dalam pembuatan produk abon dan bakso ikan. Peserta juga diberikan pengenalan alat dan bahan penunjang dalam pembuatannya. Setelah diberikan penyuluhan materi tentang proses pembuatan abon dan bakso ikan, mitra PKK dilakukan pendampingan dalam melakukan proses pembuatan produk abon dan bakso ikan. Metode pembuatan abon ikan yang digunakan yaitu dilakukan dengan cara pengukusan ikan, memisahkan daging dari tulangnya, penghalusan daging disuir kecil-kecil, penghalusan bumbu dan rempah kemudian penumisan daging ikan yang dicampur dengan bumbu dan rempah hingga menjadi berwarna keemasan. Sedangkan metode pengolahan bakso ikan yaitu dengan cara memisahkan daging ikan dari tulangnya, menghaluskan daging ikan, pengadonan, setelah itu pencetakan bakso, kemudian perebusan.

Setelah proses produksi selesai, dilanjutkan dengan pengemasan produk. Tim pelaksana program hibah bina desa juga memberikan penyuluhan tentang mengemas produk dengan baik dan rapi agar menarik minat pembeli sehingga siap dipasarkan. 


\section{HASIL DAN KETERCAPAIAN SASARAN}

Kegiatan pelatihan dilaksanakan di aula kantor Desa Tanjung Taruna pada hari Sabtu 14 September 2019. Peserta pelatihan yang hadir berjumlah 38 orang masyarakat/anggota PKK desa (Gambar 4). Kegiatan pelatihan ini dihadiri oleh Kepala Desa Tanjung Taruna, perangkat desa, PMD Kabupaten Pulang Pisau yaitu dari P3MD (Pak M. Latiful/TA TTG Kab P Pisau, Bu Nur/PD Kec Jabiren, dan Pak Devy/PLD Kec Jabiren) dan masyarakat setempat.

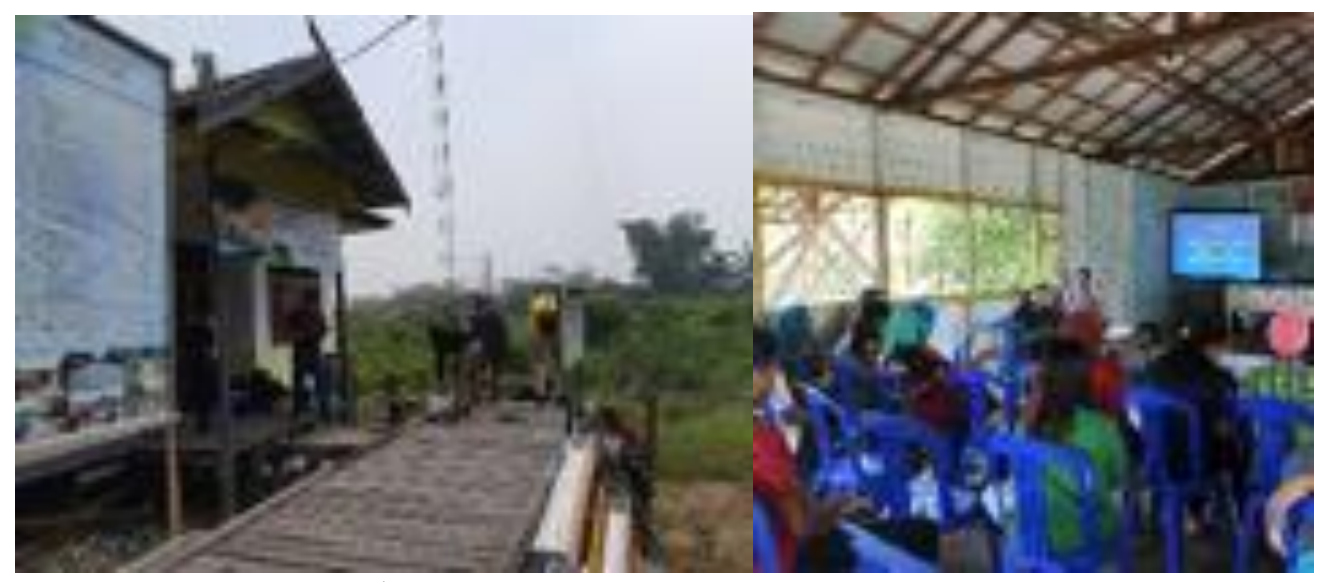

A

B

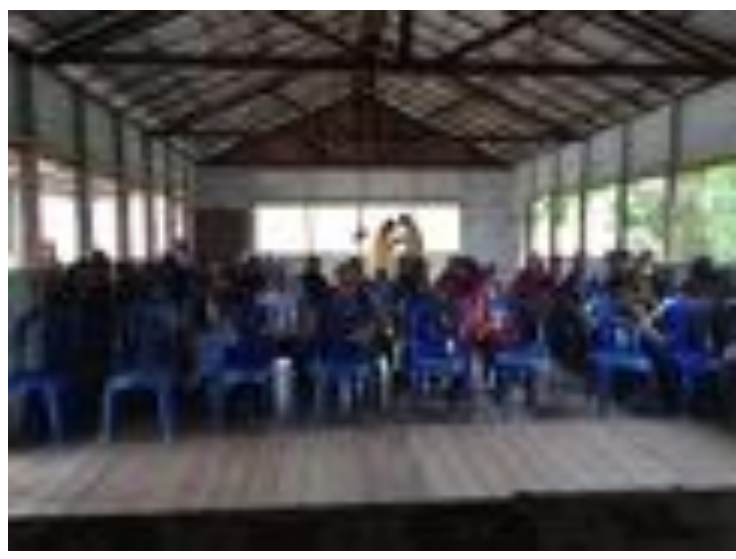

A

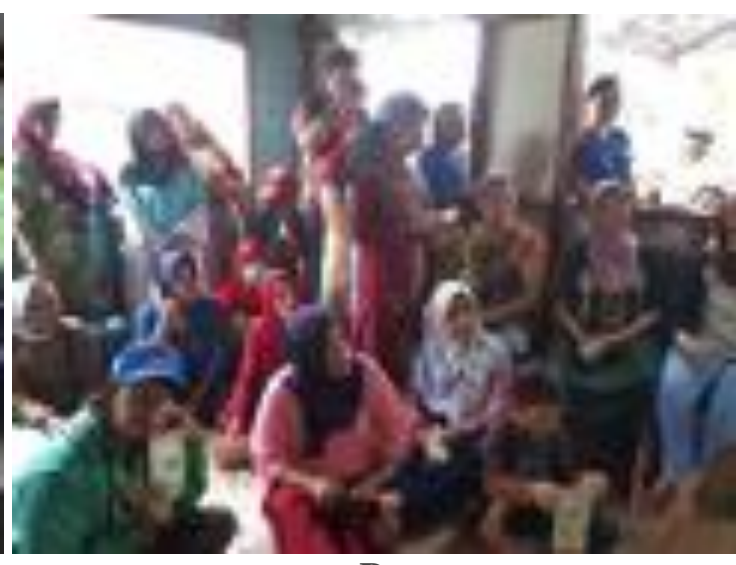

B

Gambar 4. Sosialisasi Kegiatan. A. Tempat Pelaksanaan Kegiatan. B-C. Sosialisasi Program. D. Peserta Yang Mengikuti Kegiatan

Pelatihan pembuatan produk abon dan bakso dengan memanfaatkan dari hasil nelayan masyarakat sekitar. Pada saat kegiatan diberikan pamflet cara pembuatan abon dan bakso ikan dengan bahan utama yaitu ikan gabus dan ikan patin. Setelah pamflet pembuatan abon dan bakso ikan, masyarakat diarahkan pada cara pengemasan produk hasil olahan ikan tersebut. Pelatihan pembuatan abon (Gambar 5). Proses pembuatan bakso (Gambar 6). 


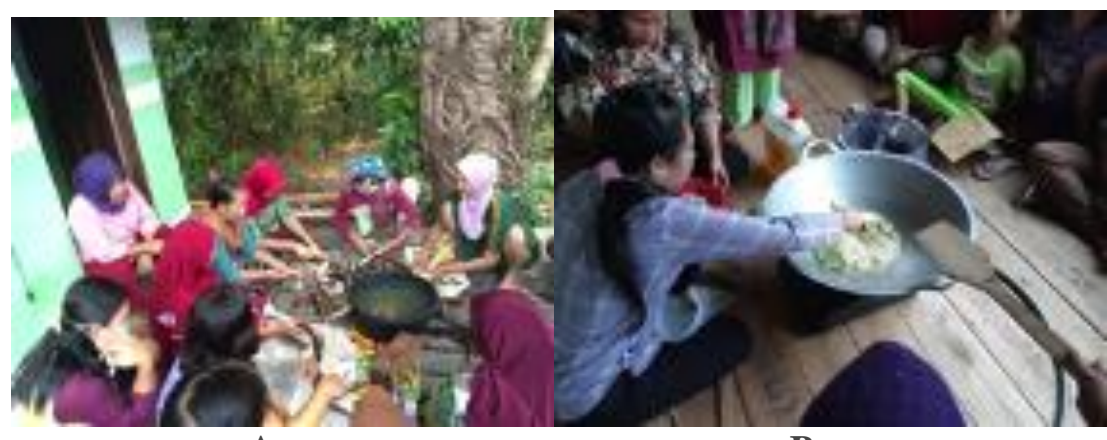

A

B

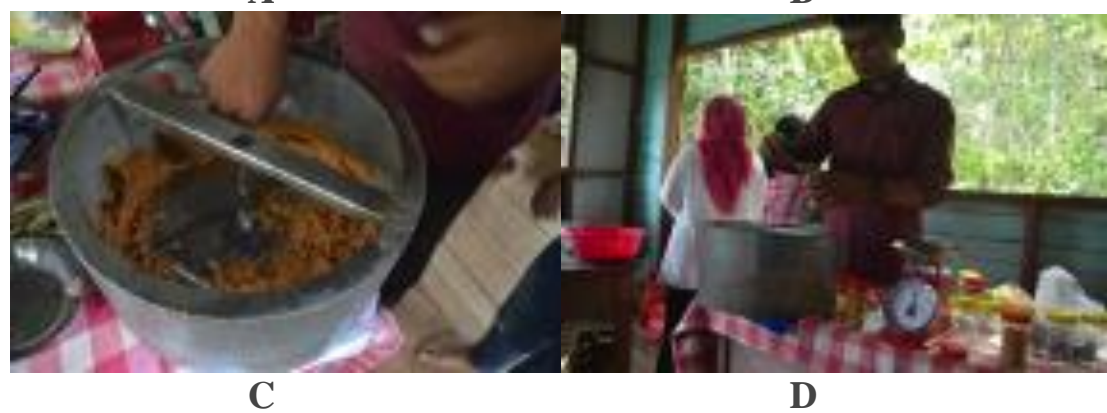

Gambar 5. Pelaksanaan Pelatihan Abon. A. Pembersihan ikan. B. Pencampuran bahan. C. Pengeringan Abon. D. Pengemasan Abon

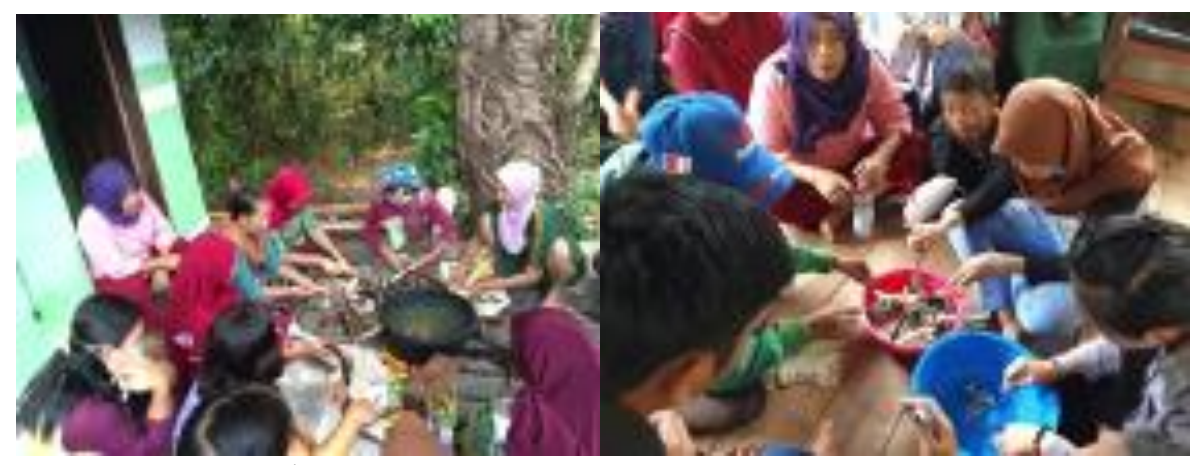

$\mathbf{A}$

B

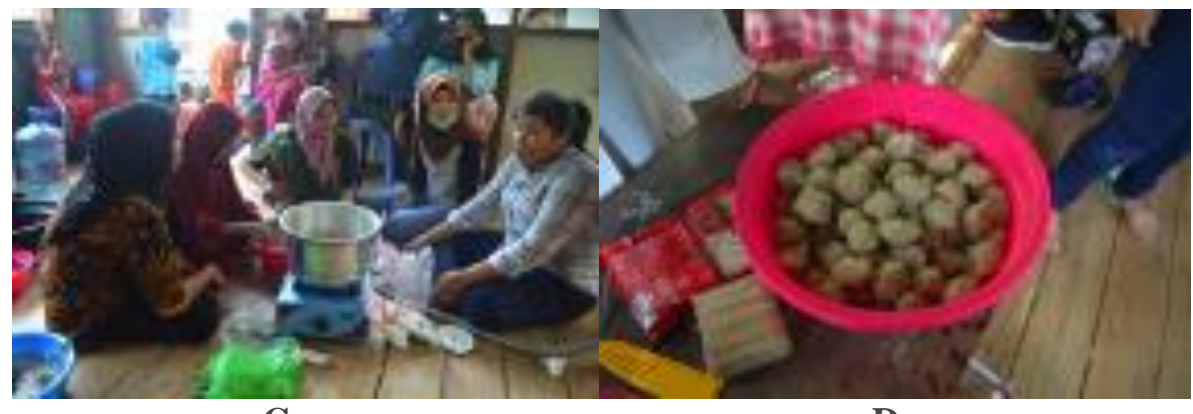

C

D

Gambar 6. Pelaksanaan Pelatihan Bakso. A. Pembersihan ikan. B. Pencampuran bahan. C. Perebusan Bakso. D. Hasil Bakso Siap dikemas

Hasil dari praktik pengolahan ikan patin dan ikan gabus di desa Tanjung Taruna dalam bentuk produk yang telah dikemas (Gambar 7 dan 8). Dengan adanya keterampilan baru yang dipelajari dalam mengolah ikan, maka ibu-ibu dapat memproduksi abon dan bakso ikan dalam skala rumah tangga ataupun skala usaha, sehingga mampu membantu perekonomian rumah tangga. Potensi pembuatan abon dan bakso ikan untuk dikembangkan dalam industri rumah tangga didukung oleh manfaatnya yang praktis dan tahan lama. 


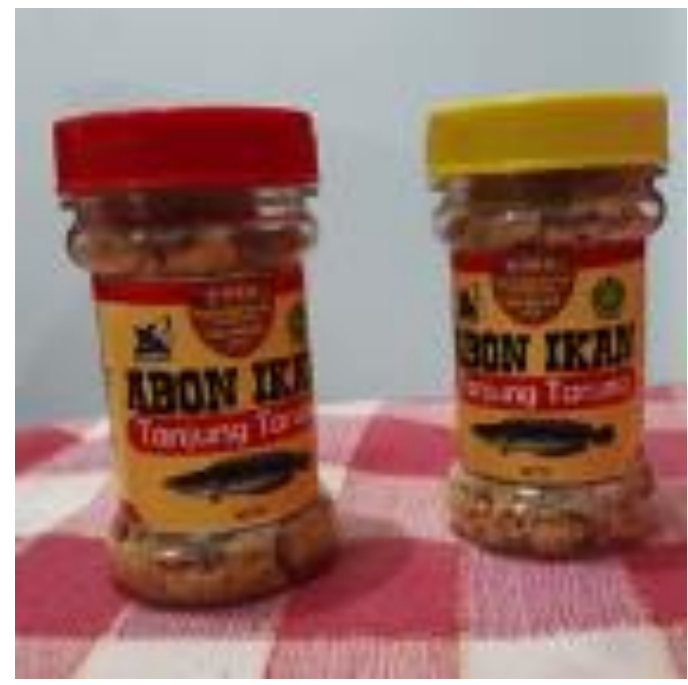

Gambar 7. Hasil Abon ikan

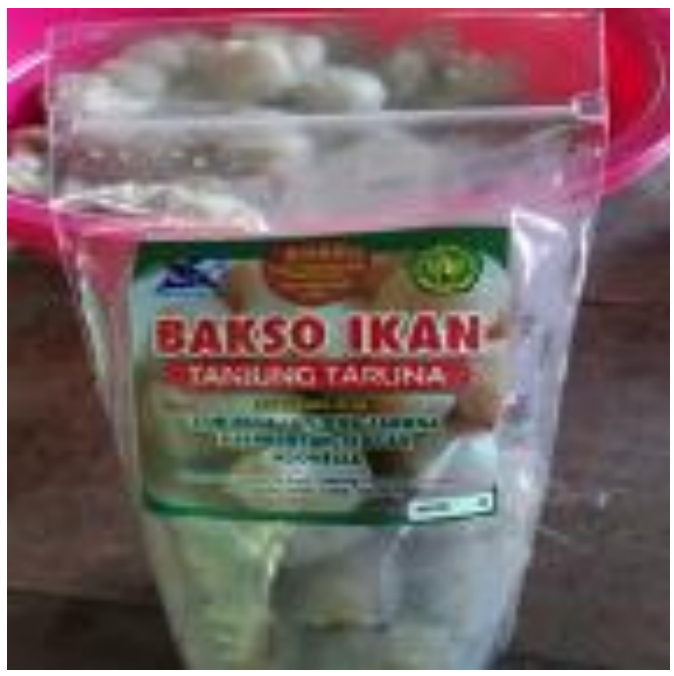

Gambar 8. Hasil Bakso Ikan

Peserta pelatihan menunjukkan antusiasme tinggi selama proses praktek pembuatan abon dan bakso ikan. Antusiasme tersebut ditunjukkan dengan respon peserta yang sangat baik dalam menerima materi mengenai abon dan bakso ikan serta kemauan peserta untuk terlibat dalam setiap tahap proses pembuatannya. Antusiasme peserta tersebut dapat meningkatkan pemberdayaan ibu-ibu dalam bidang pengolahan pangan sehingga ikan yang sangat melimpah, dapat dimanfaatkan dan dikembangkan menjadi olahan pangan yang memiliki nilai ekonomi tinggi. Pelaksanaan kegiatan program hibah bina desa ini diadakan evaluasi kegiatan dengan hasil pelatihan antara lain dapat terlihat dari hasil kuesioner peserta, 95,5\% peserta pelatihan menjadi bertambah pengetahuan dan dapat mengolah hasil ikan dari sumberdaya alamnya untuk diolah menjadi bakso ikan dan abon ikan dapat dijadikan sumber pendapatan rumah tangga. Setelah mengikuti kegiatan sebagian besar peserta sangat merasakan manfaatnya dan memberi nilai positif, selanjutnya berdasarkan saran dan masukan peserta, perlu diadakan kegiatan lanjutan agar peserta dapat mengevaluasi hasil yang telah dijalankan dalam hal pengolahan ikan. Guna keberlanjutan dalam pemasaran tim pelaksana program hibah bina desa telah mendapatkan wadah pemasaran produk hasil olahan ikan yaitu toko oleh-oleh Fauzi, toko souvenir New Singapore, toko souvenir Permata Rahmah, dan kantor PLUT-KUMKM.

Dalam pelaksanaanya terdapat beberapa kendala yang dihadapi yaitu fasilitas jalan yang masih tanah (Gambar 1), sehingga apabila hujan maka jalan akan menjadi becek dan jalan menuju desa sulit untuk diakses mobil untuk mengangkut barang kegiatan karena menggunakan jembatan panggung (Gambar 1) yang hanya 
bisa digunakan oleh pengendara motor, sehingga untuk pengangkutan barang menuju Desa Tanjung Taruna harus menggunakan gerobak masyarakat setempat.

\section{KESIMPULAN}

Program pelatihan dan pendampingan dalam mengelola sumberdaya hasil perikanan di desa Tanjung Taruna dapat disimpulkan bahwa:

1. Masyarakat desa Tanjung Taruna sangat berantusias mengikuti program pelatihan dan pendampingan pengelolaan sumberdaya hasil perikanan.

2. Masyarakat menjadi mempunyai keterampilan dalam mengolah hasil perikanan menjadi bakso dan abon ikan.

3. Masyarakat menjadi dapat mengemas bakso dan abon ikan dengan baik.

4. Masyarakat sudah mendapatkan tempat untuk memasarkan bakso dan abon ikan.

\section{DAFTAR PUSTAKA}

Andriani, R., Sandra dan Norhayati. 2018. Profil Desa Tanjung Taruna Kecamatan Jabiren Raya Kabupaten Pulang Pisau Provinsi Kalimantan Tengah. Program Desa Peduli Gambut Badan Restorasi Gambut Deputi Bidang Edukasi, Sosialisasi, Partisipasi Dan Kemitraan. (https://brg.go.id/wp-content/uploads/2019/03/FIX-KaltengPulang-Pisau-Jabiren-Raya-Desa-Tanjung-Taruna.pdf).

Erlyani, R. 2015. Bakso Ikan Tenggiri Kenyal Tanpa Borax. (https://cookpad.com/id/resep/246408-bakso-ikan-tenggirikenyal-tanpa-borax).

Min, M. 2017. Resep dan Cara Mudah Membuat Abon Ikan. (https://www.kompasiana.com/muslimin11/59e968b6c226f95a994b2c42/resep-dan-cara-mudah-membuat-abonikan).

Oktavianawati, I., dan N. Widya. 2017. Pengolahan Ikan Patin Menjadi Produk Makanan Patin, Presto, Bakso Dan Nugget Di Semboro Jember. Jurnal ABDI, 2(2), 40-44.

Pratama, R. I., I. Rostiani, dan N. Kurniawati, 2017. Pemberdayaan Masyarakat Melalui Peningkatan Keterampilan Produk Olahan Hasil Perikanan Wilayah Yang Terkena Dampak Genangan Jatigede Kabupaten Sumedang. Jurnal Pengabdian Kepada Masyarakat, 1(1), 60-63. 